\title{
Usability of a Wearable Camera System for Dementia Family Caregivers
}

\author{
Judith T. Matthews, PhD, MPH, RN ${ }^{1,2^{*}}$; Jennifer H. Lingler, PhD, CRNP ${ }^{2,3}$; \\ Grace B. Campbell, PhD, MSW, CRRN²; Amanda E. Hunsaker, MPH, LSW ${ }^{1,4}$; \\ Lu Hu, MSN²; Bernardo R. Pires, PhD ${ }^{5}$; Martial Hebert, PhD $^{5}$ and \\ Richard Schulz, PhD ${ }^{1,6}$ \\ ${ }^{1}$ University Center for Social and Urban Research, University of Pittsburgh \\ ${ }^{2}$ School of Nursing, University of Pittsburgh \\ ${ }^{3}$ Alzheimer Disease Research Center, University of Pittsburgh \\ ${ }^{4}$ School of Social Work, University of Pittsburgh \\ Pittsburgh, PA, USA \\ ${ }^{5}$ The Robotics Institute, School of Computer Science, Carnegie Mellon University, \\ Pittsburgh, PA, USA \\ ${ }^{6}$ Department of Psychiatry, School of Medicine, University of Pittsburgh, \\ Pittsburgh, PA, USA
}

Submitted July 2014. Accepted for publication March 2015.

\begin{abstract}
Health care providers typically rely on family caregivers (CG) of persons with dementia (PWD) to describe difficult behaviors manifested by their underlying disease. Although invaluable, such reports may be selective or biased during brief medical encounters. Our team explored the usability of a wearable camera system with 9 caregiving dyads (CGs: 3 males, 6 females, $67.00 \pm 14.95$ years; PWDs: 2 males, 7 females, $80.00 \pm 3.81$ years, MMSE 17.33 \pm 8.86) who recorded 79 salient events over a combined total of 140 hours of data capture, from 3 to 7 days of wear per CG. Prior to using the system, CGs assessed its benefits to be worth the invasion of privacy; post-wear privacy concerns did not differ significantly. CGs rated the system easy to learn to use, although cumbersome and obtrusive. Few negative reactions by PWDs were reported or evident in resulting video. Our findings suggest that CGs can and will wear a camera system to reveal their daily caregiving challenges to health care providers.
\end{abstract}

Keywords: family caregiving, dementia, wearable technology, mobile health

*Corresponding author: Judith T. Matthews, University of Pittsburgh, University Center for Social and Urban Research, 3343 Forbes Avenue, Pittsburgh, PA 15260. Phone: (412) 624-3776. Fax: (412) 624-4810. Email: jtmatt@pitt.edu. Other authors: linglerj@pitt.edu; gbc3@pitt.edu; aeh30@pitt.edu; luh16@pitt.edu; bpires@cs.cmu.edu; hebert@cs.cmu.edu; schulz@pitt.edu. 


\section{INTRODUCTION}

Research over the last three decades has generated a vast literature describing the challenges of family caregiving for persons with dementia [1], a syndrome resulting from neurodegenerative disorders which include Alzheimer's disease, vascular dementia, dementia with Lewy bodies, and frontotemporal dementia and affect 35.6 million people worldwide [2]. Alzheimer's disease alone afflicts 5.2 million Americans. It accounts for $60 \%-80 \%$ of persons with dementia in this country and often co-occurs with other forms of dementia. At present an estimated 15.5 million family and other unpaid caregivers provide 17.7 billion hours of care to these individuals, a mere foreshadowing of the increase in demand for informal care anticipated as the prevalence of dementia triples by $2050[3,4]$. The burgeoning of this population underscores the need for objective methods of assessing how family caregivers deal with difficult aspects of dementia, to inform tailored interventions aimed at strengthening their caregiving knowledge and skills.

\subsection{Challenges of Dementia Caregiving}

Changes in personality and progressive deterioration in memory, thinking, and ability to perform activities of daily living result in persons with dementia relying increasingly on others over time to meet their most basic needs. Family caregivers of persons with moderate or severe dementia face formidable challenges contending with these changes that vary in timing and intensity for specific diseases [5-7]. Regardless of disease trajectory, the distress experienced by family caregivers is pervasive, if not universal, and has potentially deleterious effects on the caregiver's physical and mental health and quality of life [1, 8-11].

Care-recipient behaviors commonly identified as difficult by family caregivers increase the time demands and subjective burden of caregiving. They also increase direct (e.g., medical visits, hospitalizations, medications, home health care, adult day care, home-delivered meals, and respite services) and indirect costs (e.g., time away from work) of dementia care [12] and constitute one of the major reasons for institutional placement [13]. Particularly problematic are resistive, repetitive, and agitated or inappropriate behaviors that affect health, safety, and social discourse [14, 15]. These behaviors include repetitive questioning; refusing help; resisting care; being agitated, irritated, argumentative, or combative; and experiencing hallucinations, depression, apathy, elation, anxiety, impulsivity, or disinhibition. Problematic behaviors also include being delusional; waking and wandering at night; being incontinent; exhibiting aberrant motor behaviors; and jeopardizing one's own and others' safety in relation to medications, home security, and household appliance use [9, 16-17].

Patience, intuition, and trial-and-error suffice in defusing some of these difficult behaviors, but family caregivers eventually find their efforts insufficient as symptoms of dementia fluctuate and worsen. Frustrated by limited success with their repertoire of strategies, or anxious for anticipatory guidance for handling these situations, family caregivers often seek suggestions for dealing with their family members' decline when they accompany persons with dementia to medical appointments. 
This quest for guidance is highly likely, given that upwards of $90 \%$ of persons with dementia experience a difficult behavior of one type or another over the course of their disease [18].

The scientific foundation regarding the challenges of caregiving is based largely on caregivers' self-report [19-24] rather than direct or prolonged observation of the caregiving dyad $[25,26]$. Unlike the abundance of empirical data (e.g., physical examination findings and results of lab tests and medical procedures) available to clinicians to diagnose health conditions and evaluate response to treatment, objective data are lacking for nuanced assessment of caregiving issues at home. Indeed, health care providers rely primarily, if not exclusively, on information provided by the caregiver to formulate recommendations and evaluate their effect. Informed principally by what the caregiver recalls or chooses to disclose, typically in the presence of the person with dementia during brief medical encounters [27], health care providers may not realize the frequency or intensity of difficult behaviors and the contextual triggers that may contribute to caregiver distress. They can only surmise how the home environment, disruptions in routine, and the caregiver's manner of avoiding or responding to such behaviors influence the evolution of events surrounding difficult behaviors and the dyad's interactions, especially as dementia progresses.

\subsection{Video Capture of Behavior and Dyadic Interaction}

Video recording offers an objective means of capturing behavioral manifestations of dementia and the interpersonal dynamics of caregiving dyads, especially when performed in a manner that preserves the authenticity of their interaction. Supplying dementia caregivers with a webcam-equipped laptop and asking them to record or stream the dementia-related challenges they face at home has been shown to facilitate clinical discussion of evidence-based strategies for handling specific concerns. Williams et al. [26] demonstrated the feasibility of such a system in a single case study in which a family caregiver recorded communication and behavioral difficulties exhibited by the care-recipient. The laptop and webcam operated continuously over 3 months but only retained video when the caregiver pressed a trigger to activate the system. In addition to forwarding data capture, each triggered segment included what had transpired during the 5 minutes prior to activation. An interdisciplinary team reviewed the uploaded video weekly, and a nurse discussed their recommendations with the caregiver via phone and home visits. This approach allowed the caregiver to control what was recorded, but it required anticipation of when and where salient behaviors and interactions would occur so that equipment could be in position to record. While some behaviors such as resistance to bathing or compulsive walking may follow a predictable pattern, others may be sporadic and occur in varied locations within the home.

Wearable video cameras provide a hands-free alternative to laptop webcams, as do handheld video recorders and cameras on smartphones. Typically worn at head or chest level and designed for use in naturalistic settings, wearable cameras go where the user goes. Such a system worn by a family caregiver would be well positioned and at the ready to capture dementia-related incidents. However, the limited battery capacity of commercially available systems such as the GoPro, Looxcie, and Google Glass severely 
constrains their duration of capture, making these devices impractical for recording or streaming data for several hours per day. Complex, multi-step procedures for starting and stopping recording, along with overly subtle indicators that signal when these devices are on or off further undermine the feasibility of their use in the caregiving context. In addition to affecting the timeliness (or lack thereof) of capturing representative caregiving challenges, these features and functionalities are less than ideal for family caregivers who are technology-naïve or have impaired dexterity or slowed reaction time.

Privacy protections warrant careful consideration when cameras are used in the home to reveal how household members function individually and deal with one another, especially when potentially vulnerable individuals with dementia are involved. However, evidence suggests that improved health, safety, or function resulting from constructive use of information garnered in this fashion may temper perceptions of the intrusiveness of video capture in the home. Compared with younger (age 45-64) and non-disabled counterparts, older adults (age 65 and older) and persons with disabilities have been shown to be more acceptive of in-home recording and sharing of data gathered using various types of sensors including video (with or without sound) to infer location or monitor behavior, especially when the tradeoff is enhanced safety, swifter provision of assistance, or preservation of desired living arrangements [28, 29].

\subsection{NOVEL WEARABLE CAMERA SYSTEM}

Our team has developed a wearable and wireless camera system designed to capture in situ the challenges of dementia caregiving over many hours per day at home. It goes where the user goes to capture whatever the user sees, hears, says, and does, with the user retaining control of when and what data are collected. The system consists of an outward-facing CMOS camera with a fisheye lens, a MEMS microphone that records ambient sound, and the electronics, battery, and garment necessary to support their function. The camera is mounted on a custom-printed circuit board enclosed within a plastic housing that is clipped onto the frames of overglasses, to ensure data capture at eye level and to isolate the circuit from the user's head. A cable connects the camera housing to a computer that is encased in a second housing and, in turn, embedded within the upper, inner pocket of a multi-layered "video vest" (see Figure 1).

The system is powered using a Universal Serial Bus (USB) hub and a lithium-power battery connected by cables that extend to a second pocket located below the waist within the inner layer of the vest. The USB hub is powered at a standard voltage of $5 \mathrm{~V}$ and a maximum of $500 \mathrm{~mA}$ current. The battery runs at a maximum $7.2 \mathrm{~V}$ and provides a maximum $1 \mathrm{Ah}$ at a time. Image and audio data are continuously recorded on a $32 \mathrm{~GB}$ microSD card at an average rate of 24 frames/second in 20-minute segments labeled by date and time. The microSD card resides in a flash drive holder inserted into a cable connected to the embedded computer. Components of the system, including the custommade vest, cost approximately $\$ 1,000$.

Several human factors considerations have informed our design of the system. To avoid obstructing the user's field of view, the camera housing is clipped onto either earpiece of lensless overglasses that can be worn over regular eyeglasses, if necessary. 

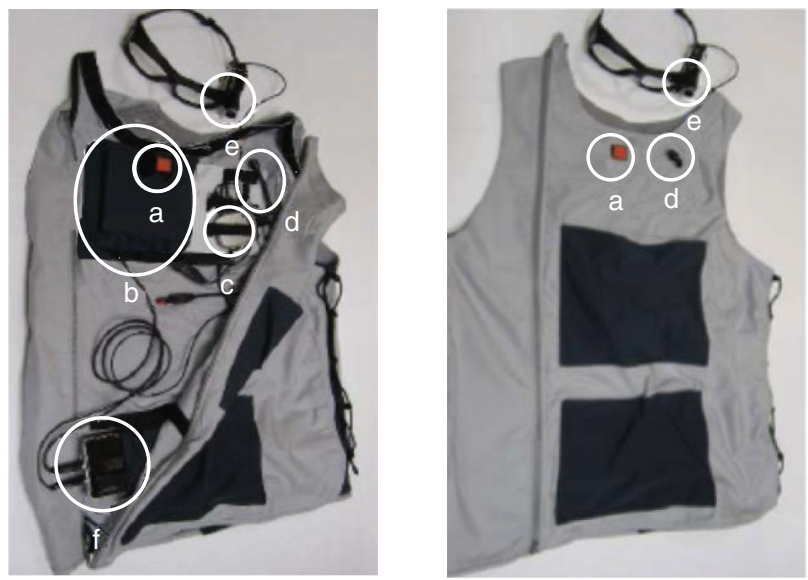

Figure 1. The wearable and wireless camera system. Left: Electronics within the video vest, including (a) the on/off button attached to (b) the embedded computer and (c) the USB hub linking (d) the microphone, computer, and (e) camera to (f) the battery. Right: Wearable system ready for use, with the on/off button and adjacent microphone accessible through openings in the upper area of the vest.

To optimize comfort, the camera and its housing are lightweight ( $<2$ ounces) and very small in size and shape. These advantages necessitate image-per-image recording offboard of the device and special software to assemble the captured images and audio data into a video format. To enable user control, a red on/off button ( 0.75 " X 0.75 ") attached to the embedded computer is accessed through an opening in the upper region of the vest front. This location for visual alerts on garments has been shown to be more easily viewable and facilitates faster reaction times than wearable displays positioned at the waist or shoulder [30]. When the battery is turned on, the on/off button illuminates and recording begins. Recording can be stopped at any time (e.g., when a visitor arrives or personal care activities are being performed that individuals prefer not to record) by pressing the lighted on/off button, and it resumes only after the button is pressed again. By default, the on/off button flashes after 10 minutes of stopped recording, thus prompting the user to press the button again unless it is pressed sooner. Once the flashing button is pressed, it remains illuminated and recording resumes. To enable free movement while using the system, we constructed the video vest to be washable; easily donned and removed; adaptable to fit men or women of varying heights, weights, and body shapes; and capable of distributing the battery weight to minimize stress on the body. The entire system (i.e., camera, overglasses, electronics, battery, and video vest) weighs 3.4 pounds.

The purpose of this paper is to describe the usability of this wearable camera system, based on initial evaluation at home by our first cohort of dementia family caregivers, as part of a larger pilot intervention trial. 


\section{METHODS}

This investigation was a minimal risk study conducted with approval by the Institutional Review Boards of the University of Pittsburgh and Carnegie Mellon University.

\subsection{Sample}

We recruited caregiving dyads through the University of Pittsburgh Alzheimer Disease Research Center, community bulletin boards, and other dementia caregiving studies whose participants had previously agreed to be contacted for future studies. Family caregivers were age 21 or older; had provided care, on average, at least 15 hours per week for at least 6 months to a community-residing care-recipient; and were able to read, speak, and understand English. They also met at least one of the following criteria: (1) reported caregiving distress evidenced by at least 2 of the following: feeling overwhelmed; feeling like often needing to cry; being angry or frustrated; feeling cut off from family or friends; reporting moderate to high levels of general stress; or feeling their health had declined; (2) experienced at least 2 problem behaviors or were "very much" or "extremely" bothered or upset by at least 1 problem behavior by the care-recipient in the last week, according to the Revised Memory and Problem Behaviors Checklist [31]; and (3) scored 17 or higher on the Zarit Burden Interview [32].

Care-recipients were age 50 or older; physician-diagnosed as having Alzheimer's disease, frontal temporal dementia, Lewy body dementia, or vascular dementia, or reported by their family caregiver to have at least one of these conditions; and able to speak and understand English prior to the onset of their dementia. Dyads were excluded if caregiving primarily occurred in a household with children under age 21 . There were no other exclusion criteria for family caregivers or care-recipients.

Ten caregiving dyads enrolled in this phase of the study, but one dyad was lost to contact after completing the baseline measures. Thus, this report focuses on 9 caregiving dyads who used our camera system. The sample included 3 male and 6 female family caregivers ranging in age from 44 to 89 , or $67.0 \pm 14.9$ years. They were spouses ( 3 husbands, 2 wives) and adult children (4 daughters) of a person with dementia. The caregivers had an average of 14 years of education, and all but two were retired or unemployed. Their care-recipients included 2 males ( 2 husbands) and 7 females ( 3 wives and 4 mothers) age 73 to $87(80.0 \pm 3.8)$ who had completed an average of 15 years of education. The sample of family caregivers was $44 \%$ white, $33 \%$ black, and $22 \%$ other, compared with proportions of $56 \%, 33 \%$, and $11 \%$, respectively, among the persons with dementia. Nonspousal caregivers were single $(n=1)$ or divorced $(n=3)$, whereas nonspousal persons with dementia were widowed $(n=2)$ or divorced $(n=2)$. Household income was $\geq \$ 50,000$ for $56 \%$ of the dyads, 7 of whom lived together, including 2 caregivers who had moved in since the onset of dementia. Two households included an adult child or grandchild who consented to retention of their images or voices recorded by our system; 5 additional nonparticipants (i.e., relatives and hired caregivers who visited frequently) provided consent for retention of their captured data. 


\subsection{Procedures}

\subsubsection{Baseline and Camera Data Collection}

Each caregiving dyad was visited at home to obtain written informed consent for participation from the family caregiver and consent or proxy consent, with assent if possible, from the person with dementia. Consent was also obtained whenever possible from non-participating household members age 21 years or older, such as adult children, siblings, or hired caregivers whose voice or images could be captured while the caregiver wore our system. Baseline data were collected regarding the caregiver's sociodemographic, health, and functional status and included a brief screen of cognitive function. The family caregiver was also interviewed regarding the caregiving situation, general personality characteristics, technology use and attitudes, and factors that could affect uptake of our wearable camera system. The same information, other than the caregiving situation, was ascertained from the caregiver for the person with dementia. If able, the person with dementia completed the brief screen of cognitive function and responded to items pertaining to technology. These baseline measures took 2.5 hours for the caregiver and up to 10 minutes for the care-recipient to complete; breaks were offered as needed. The measures were administered separately by two members of our team. While one team member interviewed the caregiver, another administered the care-recipient's baseline battery and then provided companionship for the remainder of the visit so that the caregiver could have the opportunity to speak candidly during data collection.

The next day, or as soon as possible thereafter, a second home visit was made to orient the family caregiver to our wearable system and to begin recording. Orientation took approximately 40 minutes and entailed showing the caregiver how to don and remove the overglasses and video vest, change the microSD card, replace and recharge the battery, and turn the system on and off. After practicing these procedures, the caregiver was supplied with 7 microSD cards in separate flash drive holders, two batteries, and a laptop, all of which were placed in a convenient location within the home. The caregiver received illustrated instructions and was asked to use the system for 3 to 7 days during as many waking hours per day as desired, but especially at times when difficult behaviors or interactions most commonly occurred or were anticipated. To optimize privacy, we emphasized that the caregiver would control when the system was worn and when recording occurred. The caregiver was specifically advised to stop recording in the presence of people who had not consented to participate in the study (e.g., unexpected visitors or callers) and, if desired, when performing personal care activities such as dressing, bathing, and toileting. To signal when the person with dementia was receiving medication (a common task that may or may not be difficult for the caregiver) or engaging in behaviors considered difficult, the family caregiver was asked to flash a neon card in front of the camera, as a way of visually marking each event in the recorded data. The caregiver was also asked to maintain a brief log noting when medication taking and difficult behaviors or interactions occurred.

Daily calls were made to remind the caregiver to change and recharge the battery and microSD card, insert the flash drive holder with the previous day's microSD card into the laptop, signal medication taking and problem behaviors, and complete the log. Additional 
home visits were made to provide technical support as needed. On a daily basis, data from the microSD card in the laptop were uploaded remotely via air card and LogMeIn.com to a secure server at the University Center for Social and Urban Research at the University of Pittsburgh. After the 3 to 7-day wear period, the family caregiver completed an inhome, audio-recorded interview (the focus of this report) regarding the system's usability and responded once again to statements about factors that could affect system uptake.

\subsubsection{Video for the Intervention Trial}

To provide context, we describe how the wearable camera data were managed, screened, and incorporated into the tailored intervention that a caregiver would receive within days of the usability interview. Data recorded as sequences of individual images and audio were converted into a combined video file. Because converting all data from a single day would require too much memory and computation and not be possible for the maximum duration of recording (up to 14 hours) envisioned for the system, data were converted in 20-minute segments. The resulting video segments were screened to identify and delete or anonymize the voices or images of non-consented individuals. When someone who had not consented was seen or heard, that portion of video was deleted along with its corresponding raw data, but only if it did not pertain to dementia or caregiving (e.g., a neighbor visits). For data captured without consent that involved dementia-related behavior or interactions (e.g., verbal aggression toward the mailman), identifiable images and voices were blurred or distorted, respectively. To preserve study participants' dignity and protect their privacy, we deleted or blurred all video in which they appeared undressed, regardless of whether the data were intentionally recorded, as occurred when caregivers wanted to show our team how much resistance they encountered with particular activities or how much discomfort their family member appeared to experience at times.

Two team members ( $\mathrm{SH}$ and $\mathrm{LH}$ ) screened all of the video segments to locate salient events, although due to the volume of video for this pilot work, both individuals did not screen the same segments. We defined salient events to be episodes of dementia-related behavior or caregiving interactions that were: (1) reported by the caregiver during eligibility screening or baseline data collection; (2) signaled as difficult when the caregiver flashed the neon card during data capture; and/or (3) identified by our team during screening of the video, despite not having been deemed problematic by the caregiver.

Identified salient events were reviewed by the principal investigator (JTM) who excerpted representative video clips for our team to consider during a consensus meeting focused on interpretation and development of an intervention plan tailored to the dyad's unique situation. In rare instances when team members differed in their interpretation of video content or strategies that could be helpful, the member of our team (JHL) from the Alzheimer Disease Research Center served as arbiter. The video clips were then further reduced to a set of 5-6 brief video clips that were shared with the caregiver during the subsequent intervention.

This first cohort of family caregivers viewed their brief video clips on a laptop during a home visit by a nurse (GBC) or social worker (AEH), which was followed by 
3 phone calls and provision of printed materials to reinforce the strategies discussed. The caregiver then wore our system for a second 3 to 7-day wear period to gather evidence of recommended strategies being attempted and, if so, whether they appeared to be effective. The caregiver also responded to outcome measures pertaining to caregiving, quality of life, and improvement in dementia-related behaviors after this second wear period as well as 3 months later.

To more closely approximate an intervention approach that might be feasible in an outpatient setting, the ongoing second phase of this pilot intervention trial includes a single usability interview after 3 to 5 days of system wear. The brief video clips are uploaded remotely to the laptop in the home, for viewing by the caregiver as the intervention is delivered via FaceTime. Two follow-up phone calls are being made to reinforce the intervention, and baseline measures are repeated when equipment is retrieved from the home post-intervention and again 3 months later.

\subsection{Measures}

In addition to demographic data on gender, age, race, marital status, education, employment, and income, the following measures analyzed for this report were administered by interview format. The family caregiver responded to items pertaining to caregiving and provided all other responses on behalf of him or herself and the person with dementia, unless otherwise specified.

\subsubsection{Baseline Measures}

Health and functional status: An investigator-developed code sheet was used to ascertain whether either person in the dyad had any of 26 medical conditions (e.g., arthritis, epilepsy, heart disease, diabetes, post-polio syndrome); used various assistive devices (e.g., cane, wheeled walker, manual wheelchair); or needed assistance with any of 9 activities of daily living (ADLs) such as bathing, dressing, feeding, and other personal care activities and 14 instrumental activities of daily living (IADLs) such as cooking, cleaning, shopping, and medication taking.

Cognitive function: We administered the 30-item Mini Mental State Examination (MMSE) [33] to both members of the caregiving dyad, to screen for cognitive impairment (score $\leq 24)$. This well-established instrument has demonstrated moderateto-high levels of criterion (sensitivity ranging from $69 \%$ to $100 \%$; specificity ranging from $42 \%$ to $100 \%$ ) and construct validity (correlations with other cognitive screening tests ranging from .70 to .90 ) and reliability (Cronbach's $\alpha$ ranging from .54 to .96 ) in numerous investigations [34].

Caregiving: An investigator-developed questionnaire was used to gather data regarding caregiving roles and responsibilities including duration of caregiving; availability of help from other family, friends, or hired caregivers; and level of difficulty providing ADL and IADL assistance. In addition, the 24-item Revised Memory and Behavior Problems Checklist measured the occurrence (yes/no) and extent to which the family caregiver had been bothered or upset $(0=$ not at all; $4=$ extremely) by memory and behavioral problems related to dementia in the past week, with higher scores indicative of greater frequency and reaction to such problems. Teri et al. [31] 
demonstrated high internal consistency among items for frequency (Cronbach's $\alpha=.84$ ) and reaction (Cronbach's $\alpha=.90$ ). Caregiving burden was assessed with the 12-item Zarit Caregiving Burden Interview, which has high internal consistency (Cronbach's $\alpha=.88$ ) and correlates highly (Pearson's $r=.97$ ) with the 22-item full version of the scale. Response options range from 0 (never) to 4 (nearly always). Higher scores indicate greater caregiver distress, and a total score $\geq 17$ is considered high burden [32].

Technology use: A technology use questionnaire developed by the Center for Research and Education on Aging and Technology Enhancement [35] at the University of Miami was adapted to ascertain whether 24 commonly available technologies - from DVD players and ATM machines to smartphones and tablets-were ever used or currently owned by the caregiving dyad.

Technology attitudes: A battery for measuring general attitudes toward technology, derived from the work of Mick and Fournier [36] and Parasuraman [37] and previously described by Beach et al. [29], included 18 positive and negative statements about technology that were rated $(0=$ not at all; $10=$ extremely $)$ for agreement or accuracy in describing a person's views. A second set of statements was used to appraise the importance $(0=$ not at all; $10=$ extremely $)$ of 7 factors in deciding whether to use a particular technology for assistance with daily tasks: how well it meets one's needs, ease of use, cost, attractiveness, how visible it is to others, how it affects privacy, and how safe it is to use. Finally, 5 statements measured how concerned $(1=$ not at all; $2=$ a little; $3=$ somewhat; $4=$ very) individuals were about the security of information they released to medical institutions, web sites, financial institutions, stores/restaurants, and friends/relatives (Cronbach's alpha $=.81$ ). Exploratory factor analysis has revealed 3 factors explaining $53 \%$ of the variance in general attitudes toward technology in a large sample of 1,518 middle-aged and older adults, and a single factor for security concerns (Cronbach's $\alpha=.81$ ).

\subsubsection{Pre-wear and Post-wear Measures}

Uptake factors: Before and after the initial wear period family caregivers rated the accuracy $(1=$ not at all accurate; $10=$ extremely accurate) of 9 statements describing factors that could affect system uptake. The statements pertained to ease of learning to use the system and getting it to do what was desired; physical attractiveness of the system; potential for helping to achieve goals and make life easier; nervousness and confusion about using the system correctly; invasion of privacy; and embarrassment to be seen using the system. Prior to wearing the system, caregivers rated how much the anticipated benefits of use would be worth any invasion of privacy that resulted. Postwear, they rated how flimsy the system seemed and how easy it would be to take where needed.

System usability: A semi-structured interview was used to probe perceptions of the system's appearance, ease of use, and perceived usefulness. Caregivers were asked to identify additional situations where such a wearable camera system might be useful; circumstances in which the caregiver and person with dementia would or would not be willing to use it; the reaction of the person with dementia to the system; and suggestions for design changes. 


\subsection{Analysis}

Quantitative data were analyzed using IBM SPSS version 21 for Windows. Statistical analysis involved computation of summary descriptive statistics including frequency counts and percentages for nominal and ordinal-level data and measures of central tendency and dispersion for interval or ratio-level data. The Wilcoxon Signed-Rank test was performed $(\alpha=.05$; ties omitted from computation of mean positive and negative ranks) to assess whether caregivers' baseline attitudes regarding factors potentially affecting system uptake changed after completing the wear period. Usability interview responses were qualitatively analyzed to identify additional concerns or suggestions for improving the system.

\section{RESULTS}

\subsection{Health and Caregiving Profile}

The family caregivers in this study had been providing care for their family members with dementia for an average of $6.8 \pm 7.4$ years. They had mean scores of $27.7 \pm 9.9$ on the Zarit Burden Interview and $41.4 \pm 8.8$ on the total frequency scale (Cronbach's $\alpha=.75)$ of the Revised Memory and Behavior Problems Checklist. Most $(n=7)$ received help from family and friends or hired caregivers, but all were primary caregivers. They were currently performing numerous personal care and household management tasks that had not been their responsibility prior to the onset of dementia. Most difficult were bathing, tub or shower transfers, and sustained vigilance regarding safety. Despite chronic conditions including arthritis $(n=4)$, diabetes $(n=1)$, heart disease $(n=1)$, hypertension $(n=4)$, and depression $(n=1)$, they considered themselves to be in fair to excellent health. All caregivers were screened as cognitively intact. Two caregivers needed assistance with transportation, going to medical and dental appointments, and home maintenance, and one required the use of a cane (see Table 1).

Twenty-two percent of the persons with dementia were in excellent or very good health, compared with $44 \%$ of their family caregivers. Their cognitive function varied widely (range: 0-29), with mean MMSE scores of $17.33 \pm 8.87$. In addition to the disease responsible for their dementia, all but one individual had one or more chronic conditions: arthritis $(n=6)$, diabetes $(n=2)$, heart disease $(n=3)$, hypertension $(n=4)$, and thyroid disease $(n=3)$. They exhibited little, if any, independence performing most ADL and IADL tasks, ranging from personal hygiene, toileting, and medication administration to handling meals and laundry, finances, and medical issues. Several care-recipients used assistive devices including a cane $(n=1)$, wheeled walker $(n=1)$, manual wheelchair and lift chair $(n=1)$, and transfer chair $(n=1)$ for adaptive mobility. Repetitive questioning, trouble remembering recent events or the day of the week, and being argumentative, irritable, or complaining were the most common memory and behavior problems reported by family caregivers. They were most bothered by being awakened at night and by observing apparent sadness or depressive symptoms in the person with dementia (see Table 2).

\subsection{Technology Use and Attitudes}

The households of these dyads were equipped with $11.11 \pm 3.59$ everyday devices or systems including digital appliances and entertainment and communications 
Table 1. Health and functional status of the caregiving dyads $(\mathbf{N}=9)$

\begin{tabular}{|c|c|c|c|c|}
\hline \multirow[b]{2}{*}{ Characteristic } & \multicolumn{2}{|c|}{$\begin{array}{l}\text { Family Caregiver } \\
\qquad(\mathbf{n}=9)\end{array}$} & \multicolumn{2}{|c|}{$\begin{array}{l}\text { Person with Dementia } \\
\qquad(\mathbf{n}=9)\end{array}$} \\
\hline & $\mathbf{n}$ & $\%$ & $\mathbf{n}$ & $\%$ \\
\hline \multicolumn{5}{|c|}{ Caregiver-rated health (other than problems with memory or confusion) } \\
\hline Excellent & 1 & 11 & 2 & 22 \\
\hline Very good & 3 & 33 & 0 & 0 \\
\hline Good & 2 & 22 & 1 & 11 \\
\hline Fair & 3 & 33 & 6 & 67 \\
\hline \multicolumn{5}{|l|}{ Additional Chronic Conditions } \\
\hline 0 & 1 & 11 & 1 & 11 \\
\hline $1-2$ & 6 & 67 & 3 & 33 \\
\hline 3 or more & 2 & 22 & 5 & 56 \\
\hline Mini-Mental State Examination M(SD) & 29.11 & 1.36 & 17.33 & 8.86 \\
\hline \multicolumn{5}{|l|}{ Number of ADLs Requiring Assistance $\dagger$} \\
\hline 0 & 8 & 89 & 1 & 11 \\
\hline $1-2$ & 1 & 11 & 1 & 11 \\
\hline $3-5$ & 0 & 0 & 5 & 56 \\
\hline $6+$ & 0 & 0 & 2 & 22 \\
\hline \multicolumn{5}{|l|}{ Number of IADLs Requiring Assistance $\ddagger$} \\
\hline 0 & 7 & 78 & 1 & 11 \\
\hline $1-2$ & 1 & 11 & 0 & 0 \\
\hline $3-5$ & 1 & 11 & 0 & 0 \\
\hline $6+$ & 0 & 0 & 8 & 89 \\
\hline \multicolumn{5}{|l|}{ Number of Assistive Devices Used } \\
\hline 0 & 8 & 89 & 5 & 56 \\
\hline $1-2$ & 1 & 11 & 4 & 44 \\
\hline
\end{tabular}

$\dagger$ ADLs = Activities of daily living \$IADLs = Instrumental activities of daily living

technologies. All caregivers had cell/smartphones; 7 used a computer several days per week, often to access the Internet for email, health and financial information, shopping, and games. Two persons with dementia used a computer or tablet on a limited basis for email or games.

Family caregivers gave technology in general high ratings for making life easy, convenient, and more comfortable while also reducing privacy and increasing dependency. Their ratings were lower for its role in enabling personal control, safety and security, and interpersonal connectedness, and lowest for making life stressful or complicated. When considering technology for use in their daily lives, family caregivers considered safety, functionality in relation to need, ease of use, impact on privacy, and cost to be more important than attractiveness or visibility to others (see 
Table 2. Frequency and bother of dementia-related problems, as reported by caregiver at baseline $\dagger$ and as observed in recorded video $(n=9)$

\begin{tabular}{|c|c|c|c|c|c|c|c|}
\hline \multirow[b]{2}{*}{ Problem } & \multicolumn{2}{|c|}{$\begin{array}{c}\geq \text { Once in } \\
\text { Last Week } \\
\text { (CG report) }\end{array}$} & \multicolumn{3}{|c|}{$\begin{array}{l}\text { Bothered } \\
\text { by Problem } \\
\text { (CG report) }\end{array}$} & \multicolumn{2}{|c|}{$\begin{array}{c}\text { Observed } \\
\text { in Video } \\
\text { (Recorded) }\end{array}$} \\
\hline & $\mathbf{n}$ & $\%$ & $\mathbf{n}$ & $\%$ & $\mathbf{M}$ & $\mathbf{n} \ddagger$ & $\%$ \\
\hline Forgetting what day it is & 8 & 89 & 3 & 38 & 0.50 & 1 & 11 \\
\hline Asking same question over and over & 8 & 89 & 5 & 63 & 1.38 & 3 & 33 \\
\hline Trouble remembering recent events & 6 & 67 & 3 & 50 & 1.00 & 4 & 44 \\
\hline Arguing, irritable, and/or complaining & 6 & 67 & 6 & 100 & 2.00 & 5 & 56 \\
\hline Losing or misplacing things & 5 & 56 & 4 & 80 & 1.60 & 1 & 11 \\
\hline Difficulty concentrating on a task & 4 & 44 & 2 & 50 & 0.75 & 4 & 44 \\
\hline Waking CG/other family up at night & 4 & 44 & 3 & 75 & 2.50 & 0 & 0 \\
\hline Been aggressive to others verbally & 4 & 44 & 4 & 100 & 2.75 & 1 & 11 \\
\hline Appeared sad or depressed & 4 & 44 & 2 & 50 & 1.00 & 1 & 11 \\
\hline Starting but not finishing things & 3 & 33 & 2 & 67 & 1.33 & 0 & 0 \\
\hline Appeared anxious or worried & 3 & 33 & 2 & 67 & 0.67 & 2 & 22 \\
\hline \multicolumn{8}{|l|}{ Trouble remembering significant past } \\
\hline $\begin{array}{l}\text { events } \\
\text { Crying and tearful }\end{array}$ & 3 & 33 & 3 & 100 & $\begin{array}{l}1.53 \\
1.67\end{array}$ & 0 & 0 \\
\hline Commenting about being a burden & 3 & 33 & 1 & 33 & 1.00 & 0 & 0 \\
\hline \multicolumn{8}{|l|}{ Expressing feelings of hopelessness } \\
\hline or sadness about future & 2 & 22 & 1 & 50 & 1.00 & 0 & 0 \\
\hline Doing things that embarrass you & 2 & 22 & 2 & 100 & 3.00 & 0 & 0 \\
\hline Talking loudly and rapidly & 2 & 22 & 2 & 100 & 1.00 & 0 & 0 \\
\hline Commenting about death of self or others & 1 & 11 & 1 & 100 & 2.00 & 0 & 0 \\
\hline \multicolumn{8}{|l|}{$\begin{array}{l}\text { Commenting about feeling like a failure } \\
\text { or not having worthwhile }\end{array}$} \\
\hline accomplishments in life & 1 & 11 & 1 & 100 & 4.00 & 0 & 0 \\
\hline \multicolumn{8}{|l|}{ Engaging in behavior potentially } \\
\hline dangerous to self or others & 1 & 11 & 1 & 100 & 2.00 & 4 & 44 \\
\hline Destroying property & 1 & 11 & 1 & 100 & 2.00 & 0 & 0 \\
\hline Threatened to hurt self & 0 & 0 & NA & NA & NA & 0 & 0 \\
\hline Threatened to hurt others & 0 & 0 & NA & NA & NA & 0 & 0 \\
\hline Talking about feeling lonely & 0 & 0 & NA & NA & NA & 0 & 0 \\
\hline
\end{tabular}

$\dagger$ Revised Memory and Problem Behaviors Checklist bother scores (range: 0 - 4)

NA $=$ Not applicable

Table 3). Five family caregivers were very concerned about the security of information they had released to websites and financial institutions, whereas 2 caregivers expressed the same degree of concern for information provided to medical institutions and stores 
Table 3. Attitudes toward technology in general $\uparrow$

\begin{tabular}{|c|c|c|c|c|}
\hline & \multicolumn{2}{|c|}{$\begin{array}{l}\text { Family Caregiver } \\
\qquad(\mathbf{n}=9)\end{array}$} & \multicolumn{2}{|c|}{$\begin{array}{l}\text { Person with Dementia } \\
\qquad(\mathrm{n}=5)\end{array}$} \\
\hline & $\mathbf{M}$ & (SD) & $\mathbf{M}$ & (SD) \\
\hline \multicolumn{5}{|l|}{ Positive Attitudes } \\
\hline Makes life more comfortable & 8.11 & $(1.54)$ & 9.20 & $(1.30)$ \\
\hline Makes life easy and convenient & 8.00 & $(1.58)$ & 9.20 & $(1.10)$ \\
\hline Brings people together & 6.89 & $(3.26)$ & 9.20 & $(0.84)$ \\
\hline Gives people control over their daily lives & 6.33 & $(2.45)$ & 7.20 & $(3.63)$ \\
\hline Increases personal safety and security & 5.67 & $(3.32)$ & 9.20 & $(0.84)$ \\
\hline \multicolumn{5}{|l|}{ Negative Attitudes } \\
\hline Reduces privacy & 7.78 & $(2.73)$ & 5.40 & $(4.51)$ \\
\hline Makes people dependent & 7.67 & $(2.12)$ & 4.40 & $(3.13)$ \\
\hline Makes life complicated & 5.78 & $(1.86)$ & 4.20 & $(4.09)$ \\
\hline Makes life stressful & 5.44 & $(3.43)$ & 3.00 & $(2.83)$ \\
\hline Makes people isolated & 5.44 & $(3.13)$ & 2.80 & $(2.49)$ \\
\hline \multicolumn{5}{|c|}{ Important Considerations for Using Technology } \\
\hline How safe it is to use & 9.33 & $(1.12)$ & 9.40 & $(1.39)$ \\
\hline How well it meets one's needs & 8.89 & $(1.97)$ & 9.40 & $(0.89)$ \\
\hline Ease of use & 8.44 & $(2.24)$ & 9.20 & $(1.79)$ \\
\hline How it affects privacy & 8.33 & $(2.92)$ & 7.40 & $(3.78)$ \\
\hline Cost & 7.44 & $(3.32)$ & 4.80 & $(3.90)$ \\
\hline How visible to others & 4.67 & $(3.43)$ & 5.00 & $(4.30)$ \\
\hline Attractiveness & 4.33 & $(3.74)$ & 6.00 & $(3.61)$ \\
\hline
\end{tabular}

$\dagger$ No significant differences in attitudes of caregivers and persons with dementia

or restaurants for credit/debit card transactions. The 5 persons with dementia who were able to rate the technology statements did not differ significantly from the caregivers in their attitudes, except for being less concerned about the security of credit/debit card purchases and information shared with friends and relatives.

\subsection{Usability of the System}

\subsubsection{Quantitative Findings}

Family caregivers wore our camera system during the first wear period an average of 3.25 hours per day (range: 5.5 minutes to 9.38 hours) over a combined total of 43 days, yielding 140 hours of usable video that were screened and excerpted for the intervention. Two caregivers wore the system on a single day and the other 7 family caregivers wore it from 4 to 7 days, for an average of 4.8 days per caregiver, during the hours between 7:30 AM and 12:30 AM. No caregiver appeared to have captured data 
Table 4. Hours and minutes of usable data captured by caregivers

\begin{tabular}{lcccccccccc}
\hline FC & Day 1 & Day 2 & Day 3 & Day 4 & Day 5 & Day 6 & Day 7 & Total & M & (SD) \\
\hline 1 & $2: 31$ & $3: 31$ & $4: 13$ & $3: 18$ & $3: 29$ & $4: 45$ & - & $21: 48$ & $3: 38$ & $(0: 46)$ \\
2 & $5: 23$ & $8: 24$ & $5: 09$ & $5: 24$ & $2: 38$ & $5: 05$ & $5: 09$ & $37: 14$ & $5: 19$ & $(1: 41)$ \\
3 & 4.56 & $7: 20$ & $3: 02$ & $2: 00$ & $3: 32$ & $0: 14$ & - & $21: 04$ & $3: 30$ & $(2: 27)$ \\
4 & $2: 52$ & $2: 15$ & $2: 43$ & $2: 06$ & $2: 55$ & $1: 02$ & - & $13: 54$ & $2: 19$ & $(0: 43)$ \\
5 & $4: 23$ & $1: 21$ & $3: 28$ & $4: 01$ & $2: 17$ & $2: 54$ & - & $18: 29$ & $3: 05$ & $(1: 08)$ \\
6 & $1: 10$ & - & - & - & - & - & - & $1: 10$ & NA \\
7 & $4: 57$ & $1: 42$ & $4: 48$ & $3: 57$ & - & - & - & $15: 23$ & $3: 51$ & $(1: 30)$ \\
8 & $0: 59$ & $1: 12$ & $3: 34$ & $2: 57$ & $0: 58$ & $0: 06$ & $1: 10$ & $10: 55$ & $1: 34$ & $(1: 14)$ \\
9 & $0: 40$ & - & - & - & - & - & - & $0: 40$ & \multicolumn{2}{c}{ NA } \\
\hline FC = Family caregiver & \multicolumn{7}{c}{ NA = Not Applicable } & & &
\end{tabular}

after the usual bedtime of the person with dementia. Table 4 summarizes the hours per day of usable data that each caregiver captured.

One of the caregivers who wore the system only briefly after being oriented to it cared for a person with dementia who was at times delusional and made unfounded accusations that the caregiver engaged in improper or criminal behavior. Despite expressing concern that interactions captured by our system could be negatively misinterpreted, this caregiver consented to participate and understood that activating the system to record was a matter of caregiver control. The second caregiver who wore the system on a single day withdrew from the study after completing the usability interview, indicating that the study activities were too time-consuming, given current responsibilities. This caregiver described the system, especially the battery, as too heavy but did not specify this as the reason for study withdrawal. Nevertheless, this caregiver offered unsolicited comments that reflected considerable enthusiasm for the commercial potential of the system.

Date and time stamping of captured data typically revealed a pattern of noncontinuous operation of the system, indicating that it had been turned on and off repeatedly throughout the course of a day. On average, caregivers flashed the neon card twice to signal medication taking or a difficult situation. Log data and reports by caregivers during their daily reminder calls confirmed that some days caregivers donned and removed the overglasses and video vest multiple times in order to run errands, entertain guests, or perform tasks without wearing the system. The level of detail in logs was highly variable, permitting limited insight into the timing, type, or intensity of dementia-related behaviors and the dyad's interpersonal dynamics. Six of the 9 family caregivers received additional home visits for technical support, primarily to exchange malfunctioning equipment.

During the baseline interview family caregivers anticipated that our wearable camera system would be easy to learn to use, though somewhat embarrassing to be seen using (see Table 5). Despite privacy concerns, they expected the benefits of use would be 
Table 5. Caregivers' attitudes regarding system uptake factors, pre- and post-wear $(n=9)$

\begin{tabular}{lcccccc}
\hline & $\begin{array}{c}\text { Pre-wear } \\
\text { Attitude }\end{array}$ & $\begin{array}{c}\text { Post-wear } \\
\text { (SD) }\end{array}$ & $\begin{array}{c}\text { M } \\
\text { (SD) }\end{array}$ & $\begin{array}{c}\text { Change } \\
\text { Score }\end{array}$ & $\begin{array}{c}p \text { - } \\
\text { value* }\end{array}$ \\
\hline $\begin{array}{l}\text { I am/was nervous about using the system. } \\
\text { It will be/was confusing for me to use the }\end{array}$ & $4.78(3.67)$ & $3.67(3.54)$ & -1.11 & 0.27 \\
$\begin{array}{l}\text { system correctly. } \\
\text { It will/would be embarrassing to be seen }\end{array}$ & $4.22(2.82)$ & $3.22(2.77)$ & -1.00 & 0.20 \\
$\begin{array}{l}\text { using the system. } \\
\begin{array}{l}\text { Learning to use the system will be/was } \\
\text { easy for me. }\end{array}\end{array}$ & $3.78(4.21)$ & $3.00(2.87)$ & -0.78 & 0.47 \\
$\begin{array}{l}\text { Using the system will/would help me to } \\
\text { achieve important goals. }\end{array}$ & $8.00(1.88)$ & $7.33(3.32)$ & -0.67 & 0.95 \\
$\begin{array}{l}\text { Using the system will/would make my } \\
\text { life easier. }\end{array}$ & $5.78(3.60)$ & $5.44(3.13)$ & -0.34 & 0.87 \\
$\begin{array}{l}\text { Using the system will/was be an invasion } \\
\text { of my privacy. }\end{array}$ & $4.11(3.14)$ & $3.89(3.26)$ & -0.22 & 0.78 \\
$\begin{array}{l}\text { The system is attractive from a physical } \\
\text { standpoint. }\end{array}$ & $5.89(3.89)$ & $6.11 \quad(4.14)$ & +0.22 & 0.79 \\
$\begin{array}{l}\text { It will be/was easy to get the system to do } \\
\text { what I want it to do. }\end{array}$ & $3.67(2.96)$ & $3.89(3.76)$ & +0.22 & 0.83 \\
\hline
\end{tabular}

$* \alpha=.05$

worth any invasion of privacy that resulted $(8.44 \pm 2.92)$. Caregivers gave high ratings to the system helping them to achieve important goals, but lower ratings to its potential to make life easier. They perceived it to be somewhat attractive and were moderately nervous about using it.

These perceptions of usability did not change significantly after the initial wear period, at which time family caregivers also rated the system as fairly easy to take where needed $(5.44 \pm 4.07)$ and not too flimsy $(2.89 \pm 2.93)$. The majority indicated their willingness to wear such a system when taking medications, moving about the home, eating, and helping a relative get dressed, but not when using the toilet or being out in public. Three or fewer caregivers thought that their care-recipients would be willing to wear such a system in these same situations.

Screening of the 140 hours of video resulted in identification of 16 instances of medication taking by the person with dementia and 79 salient events (i.e., portions of video depicting dementia-related behaviors or interactions deemed difficult by the caregiver or of concern to our team), the latter often observed repeatedly over the wear period. Salient events revealed caregivers contending with repetitive questioning, compulsive walking, belligerence, irritation, agitation, and apathy. Segments of video also showed caregivers struggling or frustrated by the physical challenges of 
transferring, bathing, dressing, and toileting persons whose advanced dementia was accompanied by aberrant motor function (e.g., difficulty initiating and sustaining movement), urinary incontinence, and contractures. Safety and security concerns were also identified, as when persons with dementia permitted strangers to enter their home without question or used the stove in a potentially hazardous way.

\subsubsection{Qualitative Findings}

Several suggestions emerged from the usability interviews. Caregivers thought our system would be useful for others as well as themselves, to understand the practical and emotional impact of dementia on the dyad's daily lives. They suggested that utility could also result from capturing worrisome situations that arise outside the home, particularly in unfamiliar or unsafe territory, and from using the system to facilitate medical care for homebound individuals. Recommended design improvements focused on comfort and the system's operational status. Further, caregivers reported few negative reactions to the system.

Offering perspective to self and others: Family caregivers suggested several ways that our system could provide helpful context if worn by the caregiver, the person with dementia (if feasible), or a third party. One way was to show other family members and health care providers how caregiving challenges change over time and how each member of the dyad responds to the other. Said one caregiver,

"I'll be honest with you. I'd like someone to wear it to see what I do."

Another expressed this idea:

“...if my mother's being difficult, and I have to deal with it, it could possibly point out where I handled it wrong-handled the situation-or could have handled it a better way."

A third caregiver thought that the system

“...would help me be aware of my 'tone' and make me see how my mother is reacting, because I don't always pay attention."

Capturing worrisome situations: Other caregivers suggested using the system to capture behaviors that occur away from home and to detect hazards associated with unsupervised outdoor activities. According to one caregiver,

“...when I'm driving, she escalates. So you could see what that's like. She won't go in the grocery store. She won't go in...dress shops and that kind of stuff."

Another caregiver whose care-recipient walked compulsively indoors and outside and would likely tolerate wearing the system thought it would help to monitor safety and wayfinding ability. 
Facilitating remote medical care: For persons with dementia capable of visiting their health care providers it could be highly instructive for clinicians and office personnel alike to see what it takes to prepare for and complete these medical visits, particularly when resistance and agitation persist or the patient feels overwhelmed or ignored. Recording medical visits would also enable caregivers to refresh their recollection of explanations and instructions provided. For homebound individuals, the system could provide access to remote consultation:

"I just think that it could help the doctors, because...they don't want to come into the house... And that, honestly, was the biggest problem - she went for a year without seeing a doctor in the moderate to late-stage Alzheimer's range...But this could help in that way...if it was forwarded to the doctor."

Improving wearable system design: Caregivers' ideas for improving the usability of our system were chiefly aimed at increasing comfort, reducing its weight, and keeping the user apprised of its operational status. Suggestions included providing lighter overglasses or eliminating them altogether in favor of an embedded camera in the vest at chest level; constructing the vest with lighter mesh fabric; using a smaller, lighter battery and shorter cables to connect system components; adding visual indicators of battery status and time remaining for data capture; and transmitting camera data wirelessly to the embedded computer.

Excessive bulk and the need to waterproof the system were especially concerning to caregivers who provided physical assistance with bathing, repositioning, and transfers to persons with advanced dementia. These were tasks that often placed the person with dementia in contact with the video vest and prompted caregivers to worry about discomfort to the care-recipient or damage to the system. Their suggestions also reflected concerns about reactions that would likely have occurred earlier in their care-recipients' disease trajectory. These suggestions, aimed at increasing safety and reducing the obtrusiveness of the system, were to make it smaller, with no bright colors or shiny parts to attract attention, no visible cables to grab, and no loose parts (e.g., microphone cover) to place in the mouth. We did not specifically ask caregivers whether they consistently noticed when the on/off button flashed. However, two caregivers indicated that sometimes they failed to notice it flashing until they happened to see their reflection in a mirror.

Responding to the caregiver's appearance: Mixed reactions to the system by persons with dementia were reported by family caregivers or evident in the resulting video. Most persons with dementia expressed little or no curiosity about what the caregiver was wearing but, if so, were satisfied with a simple explanation that the system was new and being tried in home situations like theirs. One caregiver indicated that the system prompted repeated questioning:

$$
\text { “...because she's totally - "Why are you wearing those?"- every } 30 \text { seconds..." }
$$

However, this behavior was rarely observed over 27 hours of data captured by the caregiver. The system never triggered apparent fear, agitation, or paranoia in the 
persons with dementia, though two caregivers noted that it influenced cooperation and prompted concern about modesty on occasion:

"When I'm trying to get her to bed, when she knew it was on tape, she actually complied."

"He looked at me kind of strange...he dressed in the bathroom because [laughing] he didn't want to get dressed-he was embarrassed of the camera."

\section{DISCUSSION}

Our findings suggest that family caregivers can and will use a wearable camera system at home to capture what transpires between themselves and their family members with dementia. This practice is especially appealing to caregivers if doing so would help health care providers - and other family members - to understand the daily challenges they face and enable the caregiver to learn more effective ways of handling these challenges. This investigation further demonstrates that our prototype system is capable of gathering objective evidence of behavioral, physical, and emotional manifestations of dementia that may be amenable to intervention.

Our sample of caregiving dyads generally reflected the sociodemographic, health, and functional profile as well as the level of burden and array of memory and problem behaviors that have typified samples in much larger studies of dementia caregiving $[3,38,39]$. Persons with dementia in our study were in poorer health than their caregivers, who often dealt with chronic diseases of their own. The types of memory and behavioral problems described and recorded by caregivers aligned well with problems widely reported by family caregivers of community-residing persons with dementia [4, 40-42]. Although several distressing aspects of dementia such as combativeness and night waking and wandering were not captured by our system during the brief wear period that only included waking hours, some family caregivers reported dealing with them at times when the system was not in use. For instance, when nighttime sleep disruption was an issue, frequent daytime napping observed in the recorded videos suggested the need for more activity throughout the day.

In the majority of cases both members of the dyad tolerated use of our system, most for several days of the wear period, signaling their implicit acceptance of the time, effort, and invasion of privacy involved in study participation. It is conceivable that their remarkably high tolerance resulted from the sense of autonomy, self-esteem, and trust they may have derived from its use. Harrefors et al. [43] identified these factors in a survey of professional caregivers (e.g., nurses, occupational and physical therapists, care assistants, and administrators of community-residing persons with dementia) who were asked how a fictitious woman with mild dementia would feel about carrying a smartphone in her pocket and wearing a digital camera around her neck to automatically record her location and daily activities, for later sorting and review of events of the day with a family member or professional caregiver. In addition to suggesting how persons with dementia rather than family caregivers might respond to wearing assistive digital technology to record their usual activities, these authors suggested that similar modes 
of capture have the potential to be both informative and empowering when shared with others.

Our caregiving dyads were typically well equipped with products such as computers, cell phones, and DVD players that are fairly commonplace in American households. The family caregivers endorsed both positive and negative attitudes toward technology in general and expressed less concern about releasing information to family members than to medical institutions or other targets. These views are consistent with the findings of Beach et al. [29] whose national survey of baby boomers and older adults revealed that having positive general attitudes toward technology was the strongest predictor of acceptance of recording and sharing information about behavior gleaned from sensing technologies (included video) at home. Other significant predictors of the acceptability of sharing such information with health care providers and family included being female, having a high school education or less or a college education or more, being comfortable using technology, viewing privacy as important but having less concern about the security of released information, and experiencing activity limitations due to physical, mental, or emotional problems. Level of disability, more than age, was shown to influence acceptance of recording and sharing this type of information. Compared with nondisabled baby boomers, older adults without disability were slightly more accepting of using sensors including video cameras for this purpose, but much less accepting than either boomers or older adults with disability.

These findings regarding acceptance are important for health care providers to consider when deciding whether a wearable camera would be a viable method for collecting data to inform their plan of care. Our findings suggest that the tradeoff between preserving privacy and obtaining guidance and support may be more acceptable to candidate caregivers than would otherwise be assumed. Even though recordings are unlikely to capture all of the challenging behaviors and situations faced at home, as was the case in our study, they provide a springboard for discussion of caregiving issues and context for assessing functional decline, disease management and caregiver respite needs, and handling of difficult behaviors by the caregiver. Additional consideration should be given to the caregiver's cognitive ability, dexterity, vision, psychological temperament, level of stress, and other human factors, much as would be done to assess whether a family caregiver of a person with an infection could safely administer intravenous antibiotic therapy at home.

We emphasized from the outset of the study that our system was a prototype that would benefit from constructive criticism of its design and performance. Equipment malfunctions that resulted in additional home visits by our team principally involved battery failures, inconsistent operation of the lighted on/off button, and intermittent recording of audio or image data rather than simultaneous recording of both. In each case, we provided a replacement component so that data collection could resume. The faulty component was further evaluated in our laboratory and corrected, ultimately improving the reliability of the system. Despite these interruptions, 7 of the 9 family caregivers persevered with wearing the system not only through this initial wear period, but also for a combined total of an additional 41 days, or 5.9 days on average, during the second 3 to 7 -day period of wear that followed receipt of their tailored intervention. 
By asking family caregivers to wear our system for as many waking hours as desired over a period of several days our intent was to capture the rhythm and patterns of their daily caregiving challenges, including variation introduced by changes in routine that could differentiate weekdays from weekends. We wanted caregivers to decide within a range of 3 to 7 days how much data capture was necessary to illustrate their concerns, and to see how long they would be willing to use the system within that timeframe. For some caregivers one day was much like the next. For others, circumstances differed from day to day due to outings or the availability of other family or hired caregivers for brief respite, or caregivers wanted to show us how they affected the care-recipient at home. It was not unexpected that all study participants did not wear our system over the minimum number of days requested, given that nonadherence to medical device use is common (e.g., see $[44,45])$. Indeed, exploring why caregivers stopped wearing the system enabled us to begin to understand what may make it unusable for some individuals or dyads.

Wearing the system rather than using a handheld video camera, which would admittedly have been much less cumbersome and obtrusive, had the advantage of having the camera at the ready, if not already recording, when a behavior or interaction occurred. The caregiver could go about usual activities throughout the home without carrying the camera or having to retrieve it from another location and turn it on while a salient event transpired, by which time the event may have passed entirely. Our view was that relying on a handheld video camera would likely have resulted in the caregiver recording much less frequently and more selectively.

In this early work we thought it prudent to gather as much data as the caregiver was willing to record over a period of up to a week, in order to begin to understand how much data could be needed to provide ample evidence of the caregiver's usual strategies for handling dementia-related challenges. Though this approach may have resulted in under-recording of salient events, the same potential bias exists when caregivers selectively describe their otherwise unobserved caregiving situation. Whether caregivers intentionally or inadvertently failed to record or signal events that they found distressing because they forgot to activate the on/off button or flash the neon card is purely a matter of conjecture. Nevertheless, we learned that by wearing our system for only a fraction of their waking hours caregivers captured many examples of the behavioral and interpersonal aspects of dementia caregiving that most distressed them, as well as evidence pointing to additional concerns (e.g., unsafe appliance use, allowing strangers into the home, agitation escalated by the caregiver's handling of a situation) that warranted our intervention. Though caregivers were not explicitly asked to validate our interpretation of these salient events, their implicit agreement was assumed (and undisputed) based on their willingness to discuss specific strategies for dealing with the challenges thus identified.

A more efficient use of the system would involve the caregiver wearing it only during the times of day or activities when distressing behaviors or interactions most commonly occur. The drawback of this approach is that previously unidentified but concerning caregiving issues may not be recorded due to the caregiver's unawareness of their import. In contrast to our system, the telehealth setup consisting of a laptop and webcam 
with "go-back-in-time" digital recording capability that was evaluated with a single caregiving dyad by Williams et al. [26] had the advantage of continuous operation. Its disadvantages were that the caregiver had to anticipate communication or behavioral difficulties and position the equipment where needed, presumably at times while these difficulties were happening, and actively trigger recording of the video. Although the duration of individual recordings was not reported, 0 to 8 videos were transmitted weekly over 3 months. Up to 3 of these videos were reviewed by the team each week, which suggests there was considerable redundancy in the content of the recordings.

Regardless of the duration of data capture, a major technical challenge of this work is culling salient events from the video that results from our system, to produce a brief but representative sample of concerning behaviors and interactions. At present this is accomplished through screening and annotating all segments of the video, a laborintensive process that is acceptable at this juncture in the research process but ultimately infeasible in health care practice. Our team has begun applying face recognition algorithms to representative segments of the video in order to identify instances when the caregiver is interacting with someone in view, typically the person with dementia. Leveraging ongoing research in machine learning and computer vision will be key to distilling hours of caregiving video into much briefer video clips that can be used to inform intervention. Machine learning, which focuses on developing computational models of learning processes so that computers can learn from the data they gather rather than merely implement instructions [46], complements computer vision methods for recognizing and automating interpretation of the two- and three-dimensional image data [47] that comprise video. In order to reduce these massive amounts of complex video data gathered in diverse home settings to an interpretable, usable level, robust algorithms will be needed in three areas: learning predictive models from video and motion sequences; addressing fundamental building blocks of temporal alignment, clustering, classification, and prediction; and recognizing objects, scenes, and actions.

Major limitations of this study suggest that our findings should be viewed with caution. The small sample size and likely selection bias introduced by recruiting caregiving dyads who had previously taken part in dementia research and dementia caregiving research in particular are readily apparent. Another potential limitation is that persons with dementia may have behaved differently if they realized they were being recorded. Likewise, caregivers may have modified their usual activities or manner of interaction, aware that their words were being recorded and their actions could be inferred from their first-person perspective. Permitting the caregiver to wear and interact with the system for part or all of the orientation day before beginning to record data would have afforded the caregiver and the person with dementia time to become acclimatized to having their words and actions captured, potentially altering our findings about the system's usability. Yet another limitation is the process by which we identified and interpreted salient events in the converted video for intervention. Though a stronger method would have entailed separate qualitative screening of the video by at least two members of the team and quantitative assessment of inter-rater reliability, limited resources precluded implementing such procedures with 140 hours of usable video. 
Notwithstanding these limitations and in keeping with principles of user-centered design [48], our small sample had the advantage of intensive exposure to our camera system for initial evaluation of its usability over several hours and days of wear. Comments from caregivers and our screening of the data suggest that, with rare exception, both members of the caregiving dyad became acclimated to our system within the first day of data capture. Our approach yielded invaluable input regarding technical shortcomings that were addressed with software upgrades, replacement of broken or malfunctioning parts, and modifications to procedures for turning the system on and off, all of which resulted in improved system reliability over the course of the study. Our approach also identified desirable features and functionalities (e.g., smaller, lighter, waterproof components; additional status indicators; wireless offloading of data from the SD card) for future iterations of wearable camera systems for dementia caregiving. More importantly, most family caregivers and persons with dementia did not reject our prototype wearable camera system, but rather viewed it as a tool in development, with the potential to gather evidence of their caregiving challenges and provide a basis for discussion of new and more effective ways of handling them.

\section{CONCLUSION}

This investigation demonstrated that family caregivers of persons with dementia are willing and able to use a novel, wearable, camera system to gather evidence of distressing dementia-related behaviors and interactions that may affect the health and safety of the caregiving dyad. Despite technical difficulties that interfered at times with its smooth operation, our system was accepted by most caregivers and their carerecipients. The system's usability would be greatly enhanced by being less cumbersome and obtrusive, and automated methods for flagging salient events are needed for the system to be useful in clinical practice. If commercially available devices such as Google Glass or the GoPro could both record longer to obviate the need for the heavy battery and vest and indicate more clearly when data are being recorded, our system would undoubtedly become obsolete. These welcome improvements would enhance the potential for health care providers to gain greater insight into the complex and often recurring challenges of day-to-day life with a person with dementia, while also providing an empirical basis for targeted strategies to prevent or mitigate difficult caregiving situations.

\section{ACKNOWLEDGMENTS}

Preparation of this manuscript was supported in part by grants from the National Institute of Nursing Research (1R21NR013450), the National Science Foundation (EEC-0540865), and the National Institute on Aging (NIH P50 AG05133), USA. We thank Michael Devyver, John Kozar, Aubrey Shick, and Arne Suppe for their technical and design contributions to this project, and Sally Hostein, Julie Klinger, and Laurel Person Mecca for their efforts with recruitment and data collection.

\section{CONFLICT OF INTEREST}

The authors indicated no potential conflicts of interest. 


\section{REFERENCES}

[1] Schulz R, Martire LM. Family caregiving of persons with dementia: Prevalence, health effects, and support strategies. American Journal of Geriatric Psychiatry, 2004, 12(3):240-249.

[2] World Health Organization and Alzheimer's Disease International. Dementia: A public health priority, 2012, WHO Press: Geneva, Switzerland.

[3] National Alliance for Caregiving. Caregiving in the U. S., 2009, Bethesda, MD.

[4] Alzheimer's Association. 2014 Alzheimer's disease facts and figures. Alzheimer's \& Dementia, 2014, 10(2):30-41.

[5] Gaugler, JE, Wall MM, Kane RL, Menk JS, Sarsour K, Johnston JA, Beusching D, Newcomer R. The effects of incident and persistent behavioral problems on change in caregiver burden and nursing home admission of persons with dementia. Medical Care, 2010, 48(10):875-883.

[6] Galvin JE, Duda JE, Kaufer DI, Lippa CF, Taylor A, Zarit SH. Lewy body dementia: caregiver burden and unmet needs. Alzheimer Disease \& Associated Disorders, 2010, 24(2):177-181.

[7] Weder NE, Aziz R, Wilkens K, Tampi RR. Frontotemporal dementias: A review. Annals of General Psychiatry, 2001, 6:15.

[8] Andrieu S, Rive B, Guilhaume C, Kurz X, Scuvée-Moreau J, Grand A, Dresse A. New assessment of dependency in demented patients: Impact on the quality of life in informal caregivers. Psychiatry and Clinical Neurosciences, 2007, 61:234-242.

[9] Etters L, Goodall D, Harrison BE. Caregiver burden among dementia patient caregivers: A review of the literature. Journal of the American Academy of Nurse Practitioners, 2008, 20:423-428.

[10] Matthews, JT, Dunbar-Jacob J, Sereika S, Schulz R, McDowell BJ. Preventive health practices: Comparison of family caregivers 50 and older. Journal of Gerontological Nursing, 2004, 30(2):46-54.

[11] Hurt C, Bhattacharyya S, Burns A, Camus V, Liperoti R, Marriott A, Nobili F, Robert P, Tsolaki M, Vellas B, Verhey F, Byrne EJ. (2008). Patient and caregiver perspectives of quality of life in dementia: An investigation of the relationship to behavioural and psychological symptoms in dementia. Dementia and Geriatric Cognitive Disorders, 2008, 26:138-146.

[12] Herrman N, Lanctôt, KL, Sambrook R, Lesnikova N, Hébert R, McCracken P, Robillard A, Nguyen $\mathrm{E}$, The COSID Investigators. The contribution of neuropsychiatric symptoms to the cost of dementia care. International Journal of Geriatric Psychiatry, 2006, 21:972-976.

[13] Yaffe K, Fox P, Newcomer R, Sands L, Lindquist K, Dane K, Covinsky KE. Patient and caregiver characteristics and nursing home placement in patients with dementia. Journal of the American Medical Association, 2002, 287(16):2090-2097.

[14] Hooker K, Bowman SR, Coehlo DP, Lim SR, Kaye J, Guariglia R, Li F. Behavioral change in persons with dementia: Relationships with mental and physical health of caregivers. Journal of Gerontology: Psychological Sciences, 2002, 57B(5):P433-P460.

[15] Merrilees J, Ketelle R. Advanced practice nursing: Meeting the caregiving challenges for families of persons with frontotemporal dementia. Clinical Nurse Specialist, 2010, 24(5):245-251.

[16] Gitlin, LN, Winter L, Dennis MP, Hodgson N, Hauck WW. Targeting and managing behavioral symptoms in individuals with dementia: A randomized trial of a nonpharmacological intervention. Journal of the American Geriatric Society, 2010, 58(8):1465-1474.

[17] Okura T, Langa KM. Caregiver burden and neuropsychiatric symptoms in older adults with cognitive impairment: The Aging, Demographics, and Memory Study (ADAMS). Alzheimer Disease \& Associated Disorders, 2011, 25(2):116-121.

[18] Mega MS, Cummings JL, Fiorello T, Gornbein J. The spectrum of behavioral changes in Alzheimer's disease. Neurology, 1996, 46:130-135.

[19] Kraus CA, Seignourel P, Balasubramanyam V, Snow AL, Wilson NA, Kunik ME, Schulz PE, Stanley MA. Cognitive-behavioral treatment for anxiety in patients with dementia: Two case studies. Journal of Psychiatric Practice, 2008, 14(3):186-192. 
[20] Hardin S, Schooley B. A story of Pick's disease: A rare form of dementia. Journal of Neuroscience Nursing, 2002, 34(3):117-122.

[21] Marrelli TM. Dementia: Complex care needing ongoing assessment. Home Health Care, 2005, 26(2):81-82.

[22] Farran CJ, Loukissa D, Perraud S, Paun O. Alzheimer's disease caregiving information and skills. Part I: Care recipient issues and concerns. Research in Nursing \& Health, 2003, 26:366-375.

[23] Farran CJ, Loukissa D, Perraud S, Paun O. Alzheimer's disease caregiving information and skills. Part II: Family caregiver issues and concerns. Research in Nursing \& Health, 2004, 27:40-51.

[24] Phillips LC, Rempusheski VF. (1986). Caring for the frail elderly at home: Toward a theoretical explanation of the dynamics of poor quality family caregiving. Advances in Nursing Science, 1986, 8(4):62-84.

[25] Mahoney EK, Trudeau SA, Penyack SE, MacLeod CE. Challenges to intervention implementation: Lessons learned in the Bathing Persons with Alzheimer's Disease at Home Study. Nursing Research, 2006, 55(2S):S10-S16.

[26] Williams K, Arthur A, Niedens M, Moushey L, Hutfles L. In-home monitoring support for dementia caregivers: A feasibility study, 2013, Clinical Nursing Research, 22(2): 139-150.

[27] Hunsaker AE, Schmidt K, Lingler JH. Discussing dementia-related behaviors during medical visits for people with Alzheimer's disease. American Journal of Alzheimer's Disease \& Other Dementias, 2010, 25(3):248-254.

[28] Beach S, Schulz R, Downs J, Matthews J, Seelman K, Barron B, Mecca LP. End-user perspectives in privacy and other trade-offs in acceptance of quality of life technologies, 2009, Proceedings of the 1st International Symposium on Quality of Life Technology, Pittsburgh, PA.

[29] Beach S, Schulz R, Downs J, Matthews J, Barron B, Seelman K. Disability, age, and informational privacy attitudes in quality of life technology applications: Results from a national web survey. ACM Transactions on Accessible Computing, 2009, 2(1), Article 5, available at http://portal.acm.org.

[30] Harrison C, Lim BY, Shick A, Hudson SE. Where to locate wearable displays? Reaction time performance of visual alerts from tip to toe. Proceedings of the $27^{\text {th }}$ Annual SIGCHI Conference on Human Factors in Computing Systems, CHI 2009, 2009, Boston, MA, 94-944.

[31] Teri L, Truax P, Logsdon R, Uomoto J, Zarit S, Vitaliano PP. Assessment of behavioral problems in dementia: The Revised Memory and Behavior Problems Checklist. Psychology and Aging, 1992, 7(4), 622-631. PMID: 1466831

[32] Bédard M, Malloy DW, Squire L, Dubois S, Lever JA, O’Donnell M. The Zarit Burden Interview: A new short version and screening version. Gerontologist, 2001, 41:652-657.

[33] Folstein MF, Folstein SE, McHugh PR. "Mini-Mental State." A practical method for grading the cognitive state of patients for the clinician. Journal of Psychiatry Research, 1975, 12(3):189-198.

[34] Tombaugh TN, McIntyre NJ. The Mini-Mental State Examination: A comprehensive review. Journal of the American Geriatrics Society, 1992, 40(9):922-935.

[35] Czaja SJ, Charness N, Fisk AD, Hertzog C, Nair SN, Rogers WA, Sharit J. Factors predicting the use of technology: Findings from the Center for Research and Education on Aging and Technology Enhancement (CREATE). Psychology \& Aging, 2006, 21:333-352.

[36] Mick DG, Fournier S. Paradoxes of technology: Consumer cognizance, emotions, and coping strategies. Journal of Consumer Research, 1998, 25:123-143.

[37] Parasuraman A. Technology Readiness Index (TRI). Journal of Service Research, 2000, 2:307-320.

[38] Ory MG, Hoffman RR, Lee JL, Tennstedt, S, Schulz R. Prevalence and impact of caregiving: A detailed comparison between dementia and nondementia caregivers. Gerontologist, 1999, 39(2):177-185

[39] Haley WE, Gitlin LN, Wisniewski SR, Mahoney DF, Coon DW, Winter L, Corcoran M, Schinfeld S, Ory M. Well-being, appraisal and coping in African-American and Causasian dementia caregivers: Findings from the REACH study. Aging \& Mental Health, 2004, 8(4):316-329. 
[40] Gitlin LN, Winter L, Dennis MP, Hodgson N, Hauck WW. A biobehavioral home-based intervention and the well-being of patients with dementia and their caregivers: The COPE randomized trial. Journal of the American Medical Association, 2010, 304(9):983-91.

[41] Belle SH, Burgio L, Burns R, Coon D, Czaja SJ, Gallagher-Thompson D, Gitlin LN, Klinger J, Koepke KM, Lee CC, Martindale-Adams J, Nichols L, Schulz R, Stahl S, Stevens A, Winter L, Zhang S. Enhancing the quality of life of dementia caregivers from different ethnic or racial groups: A randomized, controlled trial. Annals of Internal Medicine, 2006, 145(10):727-738.

[42] Burns R, Nichols LO, Martindale-Adams J, Graney MJ, Lummus A. Primary care interventions for dementia caregivers: 2-year outcomes from the REACH Study. Gerontologist, 2003, 43(4):547-555.

[43] Harrefors C, Sävenstedt S, Lundquist A, Lundquist B, Axelsson K. Professional caregivers' perceptions on how persons with mild dementia might experience the usage of a digital photo diary. The Open Nursing Journal, 2012, 6:20-29.

[44] Weaver TE, Grunstein RR. Adherence to continuous positive airway pressure therapy: The challenge to effective treatment. Proceedings of the American Thoracic Society, 2008, 5(2):173-178.

[45] Karter AJ, Parker MM, Moffet HH, Spence MM, Chan J, Ettner SL, Selby JV. Longitudinal study of new and prevalent use of self-monitoring of blood glucose. Diabetes Care, 29(8):1757-1763.

[46] Mitchell TM. Machine learning. WCB/McGraw-Hill, Boston, MA,1997.

[47] Szeliski R. Computer vision: Algorithms and applications. Springer-Verlag, London, UK, 2011

[48] Gould JD, Lewis C. Designing for usability: Key principles and what designers think. Communications of the ACM, 1985, 2(3):300-311. 


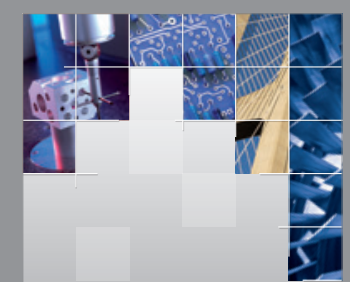

\section{Enfincering}
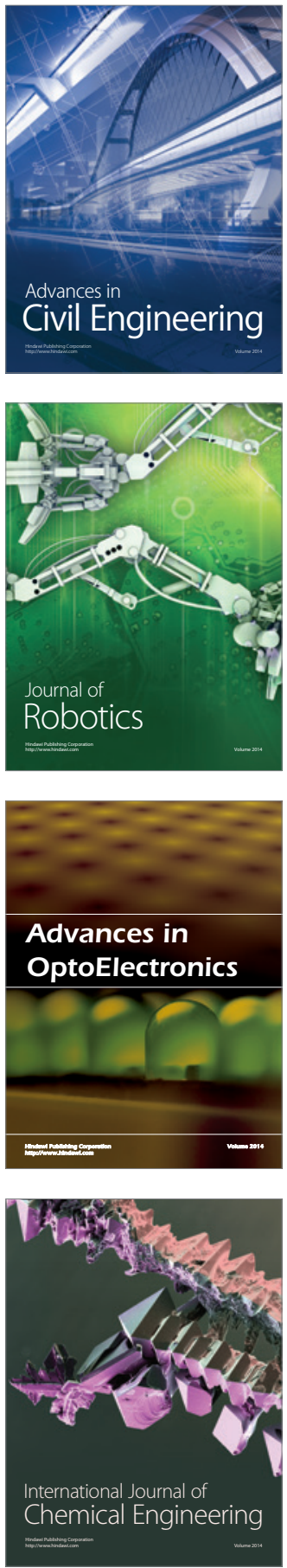

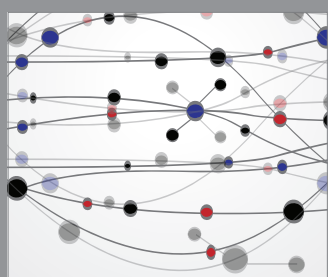

The Scientific World Journal

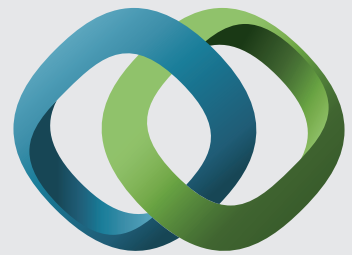

\section{Hindawi}

Submit your manuscripts at

http://www.hindawi.com
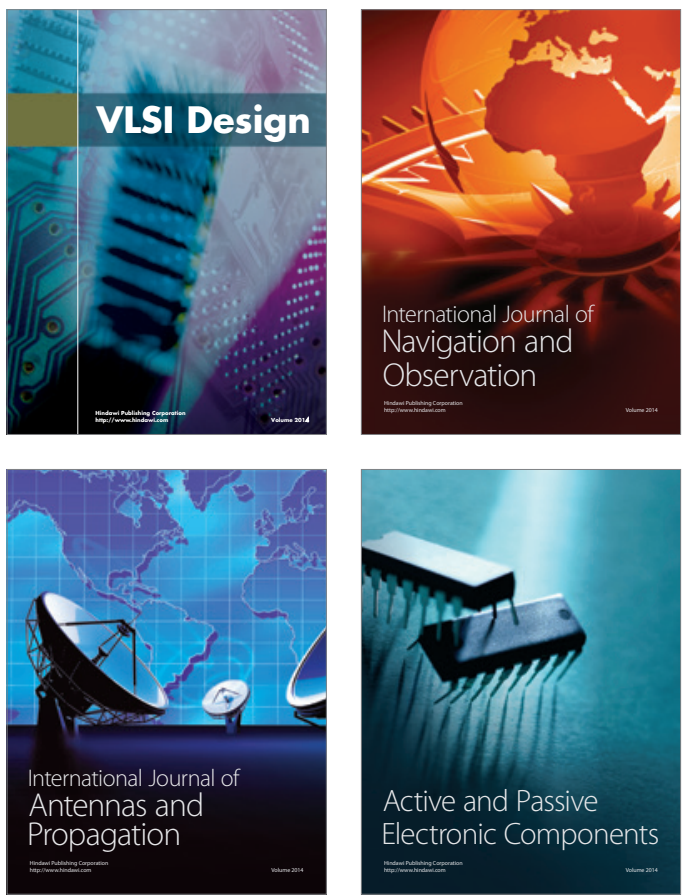
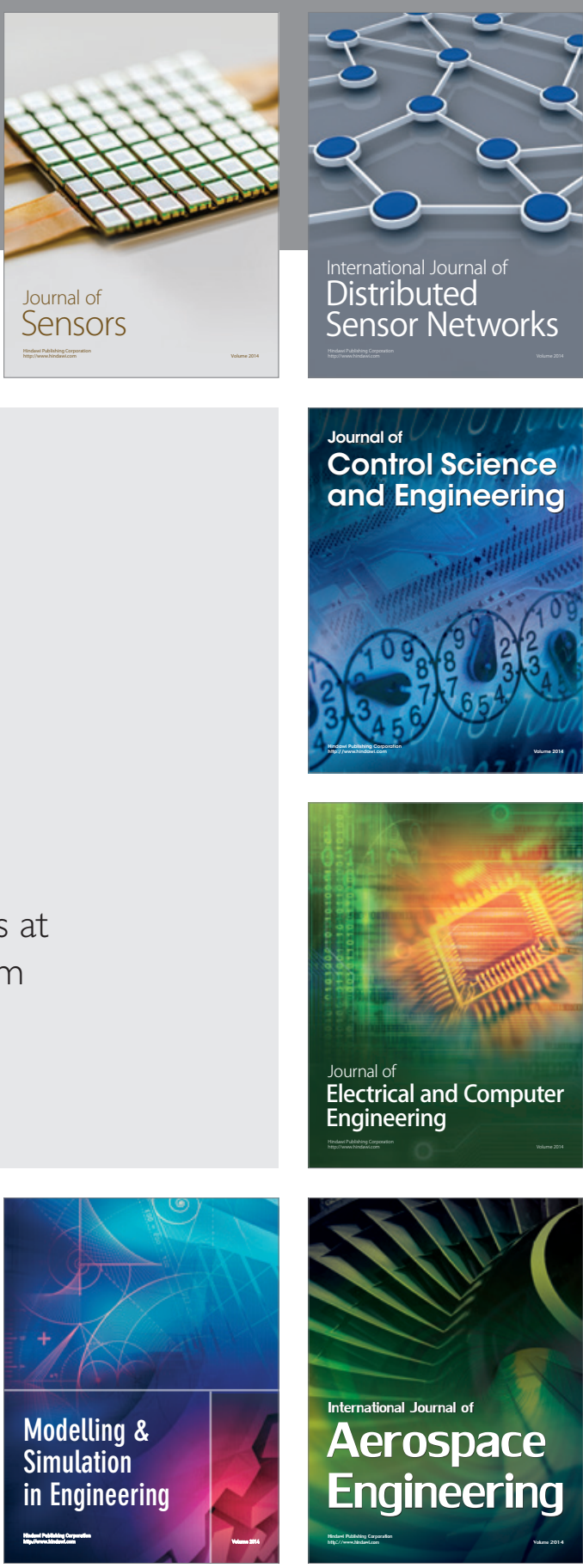

International Journal of

Distributed

Sensor Networks

Journal of

Control Science

and Engineering
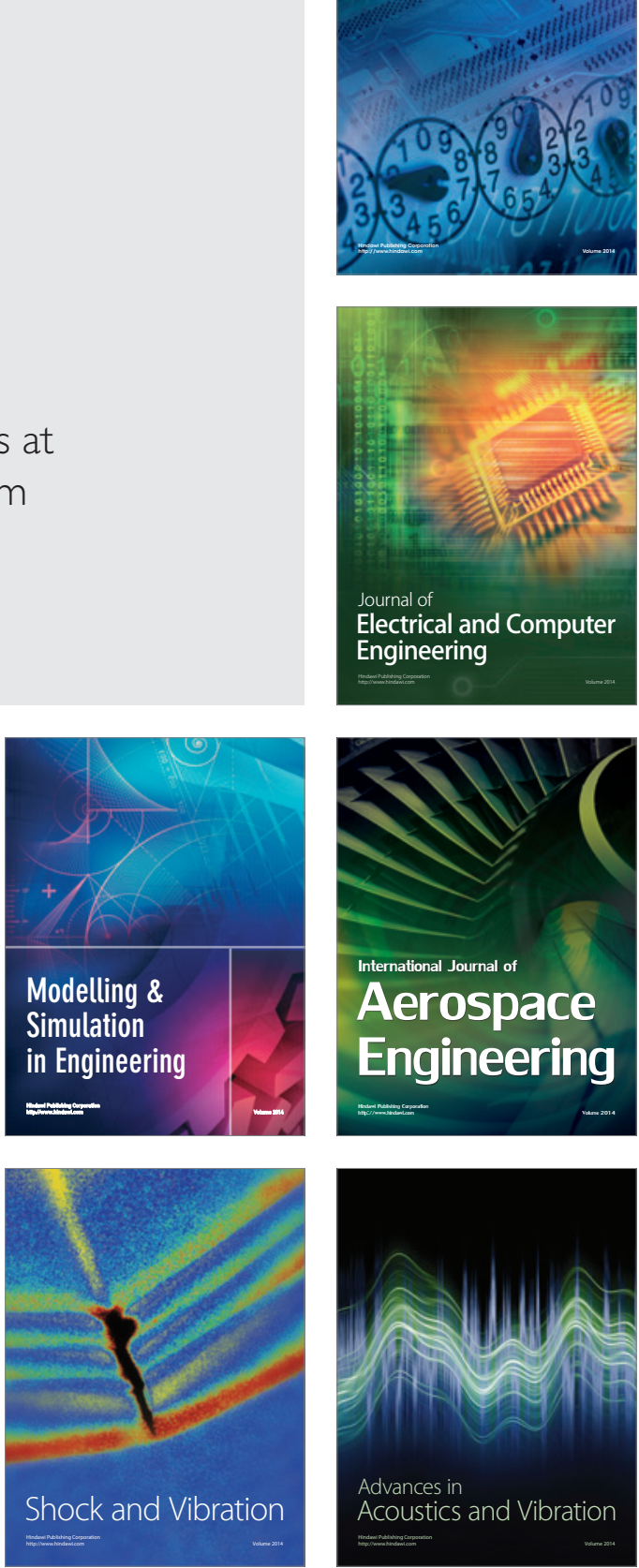